\title{
Impact of Application of the Internal Marketing on Job Satisfaction for the Employees in the Islamic Banks a Case Study of Jordan
}

\author{
Dr. Yahya Al-Khasawneh \\ Faculty of Economics and Administrative Sciences, Zarqa University, Jordan \\ y_kasawneh@yahoo.com
}

\begin{abstract}
This study aimed to measure the impact of application of the internal marketing on job satisfaction for the employees in the Islamic banks: A case study of Jordan. To achieve the objectives of this study, the researcher prepared a tool for the purpose of data collection included on (46) items, was to make sure the sincerity of the tool by presentation at a group of arbitrators, as was confirmed reliability using the coefficient (Cronbach alpha), so the reliability coefficient overall tool is (0.889). The study found a number of results, among them the following:
\end{abstract}

- The evaluation level of the study sample in Islamic banks at Jordan was a (positive), and each dimension of the internal marketing dimensions (Empowering of employees, training programs, incentives and rewards, internal communication).

- There exist a statistically significant impact at the significance level $(\alpha=0.05)$, for three dimensions of the internal marketing (training programs, incentives and rewards, internal communication), on job satisfaction for the employees in the Islamic banks.

Keywords: Internal marketing, Empowering, Training programs, Job satisfaction, Jordan.

\section{INTRODUCTION}

Have become the marketing function is not a function that are interested in providing products for sale, according to but the function that is interested by the individuals employees and prepare them for internal customers in the internal market offers to them the benefits and services and is working to raise their capacities and skills and thus improve their performance, have realized many organizations, particularly the services of it the benefits can be that you get from application of the concept of the internal marketing such as access to employees with high capabilities and skills to enable them to take responsibility and provide a high level of quality services to customers, since the external customers satisfaction is influenced by internal satisfaction, and therefore the internal marketing is considered a prerequisite for external successful marketing, as well as to raise the capabilities and skills of individuals working and continuing education for them will enable the organization to be stronger with the passage of time because of the capabilities that will be owned by the organization through individuals working It has.

Considering the importance of Islamic Banks in the economic life of this study was to identify the importance of application of the internal marketing to achieve the satisfaction of the employees in these banks and leave the effects in enhancing the performance of its staff.

\section{METHODOLOGY}

\subsection{The Study Problem \& its Questions}

The human element is an important component in the development of the institution's performance especially if the service organization, and that thanks to its competitive advantage, which can be said that the capacity of institutions to achieve their objectives will depend to a large extent on the administration's success in providing adequate motivation, and this institutions work on the advancement of this energy and rehabilitation to achieve a high degree of satisfaction of the employees so as to ensure performance of its a sophisticated. 
This can be illustrated the study problem by asking the following questions:

What is the application impact of the internal marketing on job satisfaction for the employees in Islamic banks operating in Jordan?

And branching off from this previous question a number of the following questions:

1. What is the impact of the empowerment on job satisfaction for the employees in the Islamic banks operating in Jordan?

2. What is the impact of the training programs on job satisfaction for the employees in the Islamic banks operating in Jordan?

3. What is the impact of the incentives and rewards on job satisfaction for the employees in the Islamic banks operating in Jordan?

4. What is the impact of the internal communication on job satisfaction for the employees in the Islamic banks operating in Jordan?

\subsection{The Study Importance}

Gaining study their importance through the importance of job satisfaction for the employees as it the core foundation upon which to build the institutions differentiated, who paints the objectives and plans to reach them and carried out, so the deviation will undoubtedly affect the institution thereby hindering achievement of the objectives laid down and disrupts its march. If it is easy for the institution to provide material resources they only had sometimes fail to get a human resources that wish to work and production, maintain and exploitation of its potential energy.

\subsection{The Study Objectives}

This study aims to identify the extent of the impact of the internal marketing dimensions in the level of job satisfaction from the perspective of the employees in the Islamic banks operating in Jordan through the identify of:

- Impact of the empowerment on job satisfaction for the employees in the Islamic banks operating in Jordan.

- Impact of the training programs on job satisfaction for the employees in the Islamic banks operating in Jordan.

- Impact of incentives and rewards on job satisfaction for the employees in the Islamic banks operating in Jordan.

- Impact of the internal communication on job satisfaction for the employees in the Islamic banks operating in Jordan.

\subsection{The Study Variables}

- Independent variables: The independent variables in this study, represented by the dimensions of the internal marketing (Empowering of employees, Training programs, Incentives and rewards, Internal communication).

- Dependent variable: represented by (Job satisfaction) for the employees in the Islamic banks.

\subsection{The Study Model}

Independent Variables

\begin{tabular}{||c||}
\hline Internal Marketing Dimensions \\
\hline \hline Empowering of employees \\
\hline Training programs \\
\hline Incentives and rewards \\
\hline Internal communication \\
\hline \hline
\end{tabular}

\section{Dependent Variable}

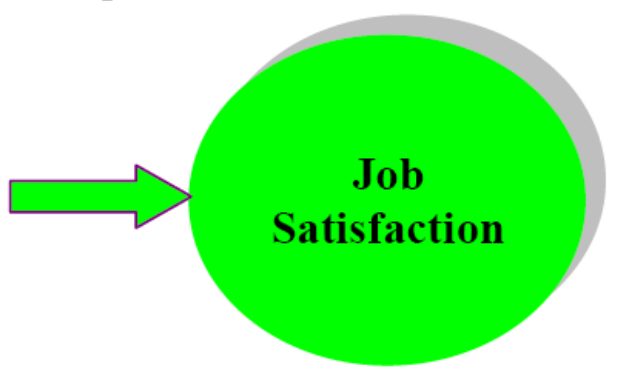

Figure1. Study Model

Source: Prepared by the researcher. 
This study aimed to identify the impact of application of the internal marketing on job satisfaction for the employees in the Islamic banks: A case study of Jordan, and to achieve that was built the following study model to illustrate the relationship between the independent variables and dependent variable of the study.

\subsection{The Study Hypotheses}

The study seeks to test the following hypotheses as a null hypothesis $\left(\mathrm{H}_{0}\right)$, as follows:

$\mathbf{H}_{\mathbf{0}}$ : There is no statistically significant impact at the significance level $(\alpha \leq 0.05)$, for the internal marketing dimensions (Empowering of employees, Training programs, Incentives and rewards, Internal communication), on job satisfaction for the employees in the Islamic banks.

The main hypothesis branching out, the following five sub-hypotheses:

$\mathbf{H}_{01}$ : There is no statistically significant impact at the significance level $(\alpha \leq 0.05)$, for the empowering of employees on job satisfaction for the employees in the Islamic banks.

$\mathbf{H}_{02}$ : There is no statistically significant impact at the significance level $(\alpha \leq 0.05)$, for the training programs on job satisfaction for the employees in the Islamic banks.

$\mathbf{H}_{03}$ : There is no statistically significant impact at the significance level $(\alpha \leq 0.05)$, for the incentives and rewards on job satisfaction for the employees in the Islamic banks.

$\mathbf{H}_{04}$ : There is no statistically significant impact at the significance level $(\alpha \leq 0.05)$, for the internal communication on job satisfaction for the employees in the Islamic banks.

\section{THEORETICAL FRAMEWORK \& LITERATURE REVIEW}

\subsection{Theoretical Framework}

\subsubsection{The Internal Marketing Concept}

Appeared in the early eighties a new term focuses on the interactions within the organization, where focused on the interaction between the employees and the increased importance of increased attention to the human element to achieve the required quality levels has been named internal marketing, participation between departments is the main key to achieve and enhance the relationship between the employees through application of the internal marketing concepts (Swaidan \& Albirdaoa, 2009: $55)$.

Internal marketing is defined as: "philosophy and activity aimed at deliver the organization's mission and its objectives for employees" (Al-Tai \& Al-Alaak, 2009: 152), also known as the "regarded the staff as internal customers and the functions strategy as internal products, they must be designed to satisfy the desires and needs of internal customers toward achieving the objectives of the organization" (Dunmore, 2002: 19). Also, Berry \& Parasurman are defined the internal marketing as: "to attract, developing, motivate and retaining qualified personnel through the functions that satisfy their needs, internal marketing is philosophy of treatment of the employees as internal and strategic customers to hurl functions as products that meet human needs" (Berry \& Parasurman, 2000: 176 ) Some see internal marketing is an "all efforts are the planned with the count marketing (derived from marketing), which is generally aimed at trying to overcome the resistance to change, and to achieve integration among employees to ensure the effective application of the strategies of the enterprise, leading to customer satisfaction, and considering the customers as internal Customers in the organization (An-Nsour, 2012: 47). Also, internal marketing defined as: "a philosophy that calls for the treatment of the employees as internal customers, keeping all the consequences of that the diagnosis of their needs and desires, and work to satisfy them as well as develop their capabilities and skills in order to improve the service levels provided by them" (Ryan \& Zahi, 2013: 10).

\subsubsection{The Internal Marketing Importance}

The internal marketing considered as management approach, it aims to reach on to customers through the development and motivate members of the organization carry out their tasks to the fullest during communication with customers, and applying the management philosophy and quality in performance of the services by all members of the organization the way they determines quality and customer satisfaction (Al-Hariri, 2006: 55). 


\section{Dr. Yahya Al-Khasawneh}

The importance of the internal marketing, including the following (Al-Shawabkeh, 2010:14-15):

- Contribute to provide a stimulating environment conducive to achieve satisfaction of the employees.

- To achieve an acceptable level of job satisfaction.

- To achieve integration and coordination in the internal activities of the organization, which related to the employees and their relationships.

- Contribute to application of the marketing philosophy internally as is the orientation towards an externally applied (i.e. the customer).

- Application specific and comprehensive strategy for the organization through which to achieve long-term objectives concerning employees with.

\subsubsection{The Internal Marketing Objectives}

The objectives that installations seeking through internal marketing to achieve represented by (AlShawabkeh, 2010: 15-16):

- Dissemination of information and exchange between work groups who interact with marketing activities aimed to take marketing decisions fair.

- Activation the incentives which are encourage the employees and motivate them to improve performance on a continuous basis.

- Develop the capabilities and skills of the employees in the industrial and service organizations.

- Supplying the organizations by the qualified employees to work the administrative functions and communication with the public.

- Helping to carry out an internal promotional campaigns to encourage the employees and activate their role in achieving the strategic objectives.

- Maintain the employees who are highly skilled, by providing them with all the material and moral work requirements.

\subsubsection{The Internal Marketing Dimensions}

\section{a. Empowering of Employees}

The Empowerment defined as: a way of managing participates through which managers and the others of the organization members to influence decision-making process, which does not specify the location of the official power as much as determines by training organization systems, bonus, participation in power, leadership style, and the organizational culture (Abu Baker 0.2015, p. 14).

The objective is to enable employees to create loyalty to the organization and the commitment of employees to its objectives, and employ their full potential for it, and engaging in continuous improvement to satisfy the wishes and expectations of customers (Tai \& Issa, 2008: 237).

There are a set of benefits that are achieved through empowerment of the employees of which (As-Sabbagh, 2008: 439-440):

- Increased commitment by the employees to implement the decisions be taken that have participated in and they have taken for themselves which helps to reach rational decisions.

- Assistance in the understanding of the employees for the conditions, objectives, possibilities, and the organization strategies, and then the commitment achieve them.

- Helping to satisfy the many desires and psychological motivation among the employees, which leads to higher of job satisfaction rate.

- Assistance in the cohesion of groups and thus achieve the organization objectives.

\section{b. The Training Programs}

A sub-system of the human resources system specializes in identifying and providing the knowledge, skills and attitudes necessary for the employees to perform their business more effectively (Abdul 
Nabi, 2010: 226). The main objective of the training in organizations by enhancing the employees commitment and personal development of the individual, develop and provide them with the necessary skills to achieve the organization objectives (Al-Tai \&. Issa, 2008: 318).

The importance of training, including the following (Al-Shawabkeh, 2010: 22):

- Address the weaknesses of the performance whether it's current or expected future performance.

- Improve the skills of the employees and developed.

- Contribute to connect the objectives of the employees with the organization objectives.

- Assist the employees to identify the organization objectives, leading to clarify the public policies.

- Provide the employees with skills may not be present they have enabling them to perform their duties required efficient.

- Assist the employees in the development of communication skills and interaction to achieve positive performance to work.

\section{c. The Incentives and Rewards}

The incentives defined as: a psychological a process draws the behavior and a tendency to act in a meaningful way to achieve the needs. And the motivation expresses the human relationship between marketing management and employees because it expresses the viewpoint of management by the employees performance and their evaluation, and the employees as human beings always seek to get the praise, excellence and they think constantly that they are doing what they should be, and comes motivate of administration them embodiment of this feeling. Where the incentives are two types a physical and moral, and the managers should enhance the positive behavior of the employees through the process of motivation.

The researches has emphasized the importance of incentives to increase the employee productivity and its association with the company, but the marketing management to choose the proper motivation type, some prefer the moral incentives, which have the greatest impact for them, while the other section prefers the material incentives and some prefer the two types together and it must choose the right time.

The incentives have a significant impact on the employees are contributing in love with the employee of the company and its association with them and thus the employee work sincerely and trying to give the company all his presents innovative ideas contribute to excellence over competitors and thus achieve a competitive advantage.

The workers who have a positive motivation to the organization helping the survival of the organization through good performance and effective dealing with customers and motivate the management to enhance their motivation and increase their loyalty to the organization and if motivate them correctly, the organization will be able to through them to achieve a competitive advantage.

\section{d. The Internal Communication}

The internal communication on all formal communication processes and informal, that occur within the organization at all job levels, where to attract, develop and motivate the employees does not work unless it is through effective communication policies to gain access in order to provide the service with desired quality (Al-Haj \& Hani, 2010: 38).

The communication policy working to facilitate the understanding and confrontation, mobility and cohesion therefore to communicate some objectives and purposes represented by (Souaad \& Zaief, 2014: 14):

1. Achieve coordination between actions and behaviors: Coordinate communication between the actions and the behaviors the organization parts, and without the organization become a set of individuals working separately from each other to perform independent tasks, without the communication lacks regulatory actions coordination and tend the organization parts to achieve the personal objectives on interest the organization objectives. 
2. Participation in information: Communication assists to exchange important information to achieve the organizational objectives, and the information in turn help to direct the individuals in performance of their tasks, and introduce them to the duties required of them, in addition to the definition of the individual by the results of their actions.

3. Decision-making: Communication represents great importance in the decision-making process, and to take a particular decision the individuals requires to certain information in order to identify the problems and implement the alternatives and evaluate their results.

4. The expression of sentimental feelings: Communication assists the individuals to participate in sentimental feelings and express their happiness, and their sorrows, fears and their confidence in the others. The communication represents an important part of the manager work where it connects the latter with all members of the organization, at all management levels, the important of communication attributed to the manager because all aspects and the work activities such as training and performance evaluation is done through the manager.

\subsection{Literature Review}

- Study of (Ryan, 2013), entitled: "Impact of the internal marketing on the employees performance in civil society organizations".

The study aimed to demonstrate the impact of procedures of the internal marketing on the employees performance in the civil society organizations, and determine the reality of thinking which embraced by the employees in the civil society organizations towards the subject, in addition to measuring and determining the service culture among the employees in civil society organizations and their contribution to enhance their performance and identify bearings preparation and development of the individuals.

And from the study findings of that the subject of the internal marketing of modern topics in the field of each of the marketing department it represents the relationship between the employees and the organization in marketing relations triangle in the area of human resources management as a call for the attention and development and enhancement of the relationship with employees, also the study found that the adoption of application of the internal marketing in organizations helping to improve the employees performance and develop their skills in order to provide the same level of distinct service quality to the customer, the researcher found that in order to create a fertile environment for the internal marketing and putting it into force must be applied procedures of the demarcation of the culture of service and human resource management policies and internal training and dissemination of marketing information among the employees.

The study found that the internal marketing success depends mainly on the performance and commitment of personnel and the civil society organizations that care the employees are also interested beneficiaries and raise their skills and level of performance because access to provide highlevel services of quality based on these employees behavior towards beneficiaries, where the view held by the beneficiary organization does not rely solely on the state of dissatisfaction from the services of these organizations as much as depends on the treatment received by the beneficiary of the employees in the organization that deals with it.

The study recommended the necessity of the attention of the civil society organizations, by application of the internal marketing and put it into effect because of its great benefits is to get the employees their high abilities and skills in handling and provide high-level services of quality to the beneficiaries in addition to the internal marketing is considered a key requirement for successful the external marketing.

- Study of (Al-Haj \& Hani, 2010), entitled: "Impact of application of the internal marketing in job satisfaction for the sales staff in the Jordanian Telecom Group".

The study aimed to identify the impact of the application of the internal marketing in job satisfaction for the sales staff in the Jordanian Telecom Group, as well as to identify and measure the impact of the internal marketing components: designation, development, internal communications, incentives, and to investigate the impact of a number of demographic factors (sex, age, experience, and education) in the relationship between the internal marketing and job satisfaction. 
The study reached to the existence of the impact of the internal marketing in job satisfaction, particularly the incentives. The study concluded that the demographics, such as age, experience years, and the education level had an impact in the relationship between the independent variables and job satisfaction, while you do not any impact for sex in this relationship, also he found that the incentives was the most influential factor in job satisfaction .

The study recommended giving greater attention to physical and moral incentives, and the need to apply the internal marketing from a marketing perspective, as this effort should be shared by the human resources and marketing management, in addition to giving greater attention to the policies of the internal communication, and activation of the connection between sales staff, marketing, and management personnel, the study also recommended studying the real causes of the weakness of job security among the sales staff.

- Study of (Al-Haddad \& Ali, 2008), entitled: "Test the validity of application of the internal marketing scale in the business environment".

The study aimed to identify the degree of the commercial banks' commitment of the research topic content of internal marketing, and disclosure of how close or move away from the content of the internal marketing, which has been tested in the business environment with the scientific standards applied by others in another environments.

And from the results of the study are interesting directors of Commercial Banks in Jordan, the removal of the internal marketing, and by the degree of importance from the perspective of the employees on the front lines with the commercial banks in Jordan, as follows: After bonuses, after development and development, after the receipts with the employees, after the leadership, and administrative support and their relationship to the behavior employees in the commercial banks operating in Jordan.

The study also found the existence of a marketing implications are characterized by the Jordanian environment to realize the concept of the internal marketing, in addition to having a large convergence of the internal marketing dimensions of prevailing in the commercial banks in Jordan with internationally recognized scientific standards.

- Study of (Dawn \& Timothy, 2002), entitled: "The internal marketing, description for the success of organizations".

The study aimed to characterize and evaluate the actual practices of the strategies, policies and programs of the internal marketing for the organizations, in addition to knowing the extent of the impact of the actual practices of the strategies, policies and programs of the internal marketing on the success level of the services provided by the organizations of the study sample.

The study reached that the internal marketing not just a management philosophy, but it is a continuous process include a range of activities that should be used to achieve the objectives and goals that it want the organization, and include internal marketing plan analysis of the nature of the service organizations of the attitudes and behaviors among the employees and customers.

- Study of (Keller \& et al., 2006), entitled: Impact of the internal marketing efforts in distribution service operations".

The study aimed to identify and assess the full composition of a combination of the internal marketing and examine the benefits of the internal composition combination in order to double the importance of the variables, including the internal customer satisfaction, and performance the internal customer, and to activate orientation towards internal customer. Also, the study aimed to activate the results are used efficiently toward a proposed the internal marketing plan is to apply managers to benefit from the distribution services processes.

Study reached should assist the front office staff to arrange daily priorities in order to reach a workforce managers and attentive to the requirements of customer care.

The study recommended conducting studies to determine the application of the internal marketing workgroups, also it recommended to work other studies analyzes the communication between people, processes and technology to create an institution dedicated to the centrality its interest by customers and guiding its processes towards them. 


\section{The Method AND Procedures}

\subsection{The Study Approach}

The study relied on descriptive analytical approach, with the aim of the study sample on the variables of the study describe the responses of individuals, and measure the impact of application of the internal marketing on job satisfaction for the employees in the Islamic banks: A case study of Jordan.

\subsection{The Study Population \& its Sample}

The study population of dealing with Islamic banks operating in Jordan and consists of the most prevalent and of the Jordan Islamic Bank for Investment and Finance, Islamic International Arab Bank.

The study sample consisted of (300) employees from the Islamic Banks in Jordan. Then the distribution (300) questionnaire to respondents, were retrieved (225) questionnaire, which reached questionnaires retrieved ratio (75\%), and after review and audit questionnaires retrieved, were excluded (20) questionnaires to be infeasible because of the failure to respond to a number of items, and thus the number of valid questionnaires for statistical analysis (205) questionnaire, and reached valid questionnaires ratio of the number retrieved (91\%).

\subsection{The Study Tool}

To achieve the objectives of the study, and after returning to the administrative literature in marketing, the tool is designed to describe the impact of application of the internal marketing on job satisfaction for the employees in the Islamic banks. The tool consisted of three parts, the first part of which dealt with the personal and functional information, while the second part dealt with the internal marketing dimensions, while third part included the variable (job satisfaction). And was used (Likert Scale) to measure the degree to evaluation the internal marketing dimensions. It was the adoption of a scale to measure the internal marketing dimensions, is divided into three levels, where the calculated cut-off grade by dividing the difference between the highest value of the scale (5) and the lowest value in it (1) at three levels, namely that the cut-off grade is $\{((1-5 / 3=1.33\}$.And thus the three levels as follows:

\begin{tabular}{|c|c|c|}
\hline Low evaluation degree & Medium evaluation degree & High evaluation degree \\
\hline $1-2.33$ & $2.34-3.67$ & $3.68-5$ \\
\hline
\end{tabular}

After that was measured the tool sincerity and its reliability, as follows:

\section{a. Tool Sincerity}

Has been verified the (Face Validity) of the study tool, and through the presentation to a group of arbitrators with expertise and knowledge of literature marketing at Zarqa University, and was the aim of the arbitration verify the extent of items belonging to the study variables, an appropriate degree of drafting items Linguistically, Has been taking into account the comments of the arbitrators, where been modification reworded drafting some of items, so that the questionnaire is designed in its final form.

\section{b. Tool Reliability}

To check the questionnaire reliability, the stability coefficient was calculated for the tool (the internal consistency of the questionnaire items) using coefficient (Cronbch Alpha) coefficient, and the reliability coefficient for the overall tool is (0.889), as shown in the following Table No. (1):

Table1. Reliability (Internal Consistency of the Questionnaire items)

\begin{tabular}{|c|c|c|c|}
\hline The Variables & $\mathbf{N}$ & Cronbach Alpha & Stability Ratio \\
\hline Empowering of employees & 10 & 0.847 & $\% 84.7$ \\
\hline The training programs & 10 & 0.829 & $\% 82.9$ \\
\hline Incentives and rewards & 8 & 0.715 & $\% 71.5$ \\
\hline Internal communication & 8 & 0.794 & $\% 79.4$ \\
\hline Job satisfaction & 10 & 0.763 & $\mathbf{\% 8 8 . 9}$ \\
\hline Overall Tool & $\mathbf{4 6}$ & $\mathbf{0 . 8 8 9}$ & \\
\hline
\end{tabular}


Impact of Application of the Internal Marketing on Job Satisfaction for the Employees in the Islamic Banks a Case Study of Jordan

\subsection{The Statistical Methods}

After that was finished of the emptying the data in the computer, were used some statistical descriptive and analytical methods, which its available in the Statistical Package for Social Sciences (SPSS), in order to answer the study question and test the hypotheses, So the statistical methods that were used for the purposes of the statistical analysis of data are:

- Means and Standard Deviations.

- Simple linear regression.

- Multiple linear regression.

\section{The Statistical Analysis of Data}

The purpose of this section to present the results of statistical analysis of data subjects' responses of the study sample study, which was reached through the use of Statistical Package for Social Sciences (SPSS).

\subsection{The Results Related to the Study Question}

What the evaluation degree of the internal marketing dimensions, from the perspective of the employees at the Islamic Banks in Jordan?

To answer the study question, it has been calculated the means and standard deviations to evaluate the employees responses on each dimension of the internal marketing.

Table (2), indicates to the analysis results of the employees responses at the Islamic Banks in Jordan, about the degree to evaluate the internal marketing dimensions:

Table2. Means and Standard Deviations for the Study Variables

\begin{tabular}{|c|c|c|c|c|c|}
\hline No. & Internal Marketing Dimensions & Mean & Std. Dev. & Rank & Evaluation Degree \\
\hline 1 & Empowering of employees & 3.95 & 0.66 & 4 & High \\
\hline 2 & The training programs & 4.28 & 0.39 & 2 & High \\
\hline 3 & Incentives and rewards & 4.21 & 0.42 & 3 & High \\
\hline 4 & Internal communication & 4.31 & 0.38 & 1 & High \\
\hline
\end{tabular}

The results in Table (2), refers to the means of the internal marketing dimensions (Empowering of employees, Training programs, Incentives and rewards, Internal communication) which are equals to $(3.95,4.28,4.21,4.31)$ respectively, and all means larger than the test criteria (3) of (5) on (Likert Scale). These results indicate to possession of the employees in the Islamic Banks, a clear vision about the importance of these dimensions, which indicates that the evaluation was (positive), and with (High) degree from the perspective of the employees in the mentioned banks.

\subsection{The Results Related to Test the Hypotheses}

The researcher will test the study hypothesis and it's sub-hypotheses as follows:

$\mathbf{H}_{\mathbf{0}}$ : There is no statistically significant impact at the significance level $(\alpha \leq 0.05)$, for the internal marketing dimensions (Empowering of employees, Training programs, Incentives and rewards, Internal communication), on job satisfaction for the employees in the Islamic banks.

In order to test the validity of the study hypothesis was used the Multiple Linear Regression Analysis. As shown in table (3) below:

Table3. Results of the multiple linear regression analysis

\begin{tabular}{|c|c|c|c|c|}
\hline Internal Marketing Dimensions & Coefficients $(\boldsymbol{\beta})$ & Std. Errors & t-value & Sig. \\
\hline Constant $\left(\boldsymbol{\beta}_{0}\right)$ & 1.134 & 0.366 & 3.102 & 0.002 \\
\hline Empowering of employees & 0.075 & 0.043 & 1.763 & 0.079 \\
\hline Training programs & 0.193 & 0.080 & 2.423 & 0.016 \\
\hline Incentives and rewards & 0.164 & 0.073 & 2.238 & 0.026 \\
\hline Internal communication & 0.268 & 0.074 & 3.627 & 0.000 \\
\hline $\mathbf{R = 0 . 5 0 1}$ & \multicolumn{3}{|c|}{$\mathbf{R}^{\mathbf{2}=\mathbf{0 . 2 5 1}}$ (F) Sig. $=\mathbf{0 . 0 0 0}$} \\
\hline
\end{tabular}


The results in table (3) show that:

- Validity of multiple linear regression is proven, this is asserted by the value of calculated (F) which is (16.709) and that the statistical significance value $(0.000)$ is less than the significance level $(\alpha=0.05)$.

- The statistical significant of regression coefficients $(\beta)$ for three dimensions (Training programs, Incentives and rewards, and Internal communication) is proven, therefore, there is a statistically significance impact at the significance level $(\alpha=0.05)$ for the above dimensions on job satisfaction for the employees in the Islamic banks. Depend on the statistical significant values $(0.016,0.026$, and 0.000) respectively, and all the values less than the significance level $(\alpha=0.05)$. This means that the null hypothesis $\left(\mathrm{H}_{0}\right)$ is rejected, based on the above results.

While, the dimensions (Empowering of employees) are not proven the significance, which means that the mentioned dimensions have no impact on job satisfaction for the employees in the Islamic banks.

- The value of Determination coefficient (R2) which is (0.251) shows that the internal dimensions in the regression model (Training programs, Incentives and rewards, and Internal communication) interpret $(25.1 \%)$ of changes that happen in the (job satisfaction).

After had finished from test the study hypothesis, and was verified the existence of the impact of three dimensions of the internal marketing (Training programs, Incentives and rewards, Internal communication), should be test the impact of every dimension of the internal marketing on the (job satisfaction), which is as follows:

\subsubsection{Test the $1^{\text {st }}$ sub-hypothesis}

$\mathbf{H}_{01}$ : There is no statistically significant impact at the significance level $(\alpha \leq 0.05)$, for the empowering of employees on job satisfaction for the employees in the Islamic banks.

In order to test the validity of the $1^{\text {st }}$ sub-hypothesis was used the simple linear regression analysis. As shown in table (4) below:

Table4. Results of simple linear regression analysis

\begin{tabular}{|c|c|c|c|c|}
\hline Independent variable & $\boldsymbol{\beta}_{\mathbf{i}}$ & $\mathbf{t}$-value & Sig. & Beta \\
\hline Empowering of employees & 0.163 & 3.666 & 0.000 & 0.249 \\
\hline
\end{tabular}

The results in table (4) show that:

- The statistical significance of regression coefficient ( $\beta$ ) for the (Empowering of employees) is proven, therefore, there is a statistically significant impact at the significance level $(\alpha=0.05)$ for the above dimension on job satisfaction for the employees in the Islamic banks. Depend on the statistical significant value (0.000), and it is less than the significance level $(\alpha=0.05)$. This means that the null hypothesis $\left(\mathrm{H}_{01}\right)$ is rejected.

- The value of the standardized coefficients (Beta) calculated for the (Empowering of employees) which is (0.249), show that increase of the mentioned dimension by a unity standard deviation will lead to increase the (job satisfaction) for the employees in the Islamic banks by (24.9\%).

\subsubsection{Test the $2^{\text {nd }}$ sub-hypothesis}

$\mathbf{H}_{\mathbf{0 2}}$ : There is no statistically significant impact at the significance level $(\alpha \leq 0.05)$, for the training programs on job satisfaction for the employees in the Islamic banks.

In order to test the validity of the $2^{\text {nd }}$ sub-hypothesis was used the simple linear regression analysis. As shown in table (5) below:

Table5. Results of simple linear regression

\begin{tabular}{|c|c|c|c|c|}
\hline Independent variable & $\boldsymbol{\beta}_{\mathbf{i}}$ & $\mathbf{t}$-value & Sig. & Beta \\
\hline Training programs & 0415 & 5.801 & 0.000 & 0.377 \\
\hline
\end{tabular}

The results in table (5) show that:

- The statistical significance of regression coefficient $(\beta)$ for the (Training programs) is proven, therefore, there is a statistically significant impact at the significance level $(\alpha=0.05)$ for the above dimension on job satisfaction for the employees in the Islamic banks. Depend on the statistical 
significant value (0.000), and it is less than the significance level $(\alpha=0.05)$. This means that the null hypothesis $\left(\mathrm{H}_{02}\right)$ is rejected.

- The value of the standardized coefficients (Beta) calculated for the (Training programs) which is (0.377), show that increase of the mentioned dimension by a unity standard deviation will lead to increase the (job satisfaction) for the employees in the Islamic banks by (37.7\%).

\subsubsection{Test the $3^{\text {rd }}$ sub-hypothesis}

$\mathbf{H}_{03}$ : There is no statistically significant impact at the significance level $(\alpha \leq 0.05)$, for the incentives and rewards on job satisfaction for the employees in the Islamic banks.

In order to test the validity of the $3^{\text {rd }}$ sub-hypothesis was used the simple linear regression analysis. As shown in table (6) below:

Table6. Results of simple linear regression

\begin{tabular}{|c|c|c|c|c|}
\hline Independent variable & $\boldsymbol{\beta}_{\mathbf{i}}$ & $\mathbf{t}$-value & Sig. & Beta \\
\hline Incentives and rewards & 0.372 & 5.576 & 0.000 & 0.364 \\
\hline
\end{tabular}

The results in table (6) show that:

- The statistical significance of regression coefficient $(\beta)$ for the (Incentives and rewards) is proven, therefore, there is a statistically significant impact at the significance level $(\alpha=0.05)$ for the above dimension on job satisfaction for the employees in the Islamic banks. Depend on the statistical significant value (0.000), and it is less than the significance level $(\alpha=0.05)$. This means that the null hypothesis $\left(\mathrm{H}_{03}\right)$ is rejected.

- The value of the standardized coefficients (Beta) calculated for the (Incentives and rewards) which is $(0.364)$, show that increase of the mentioned dimension by a unity standard deviation will lead to increase the (job satisfaction) for the employees in the Islamic banks by (36.4\%).

\subsubsection{Test the $4^{\text {th }}$ sub-hypothesis}

$\mathbf{H}_{04}$ : There is no statistically significant impact at the significance level $(\alpha \leq 0.05)$, for the internal communication on job satisfaction for the employees in the Islamic banks.

In order to test the validity of the $4^{\text {th }}$ sub-hypothesis was used the simple linear regression analysis. As shown in table (7) below:

Table7. Results of simple linear regression

\begin{tabular}{|c|c|c|c|c|}
\hline Independent variable & $\boldsymbol{\beta}_{\mathbf{i}}$ & $\mathbf{t}$-value & Sig. & Beta \\
\hline Internal communication & 0.424 & 6.066 & 0.000 & 0.392 \\
\hline
\end{tabular}

The results in table (7) show that:

- The statistical significance of regression coefficient $(\beta)$ for the (Internal communication) is proven, therefore, there is a statistically significant impact at the significance level $(\alpha=0.05)$ for the above dimension on job satisfaction for the employees in the Islamic banks. Depend on the statistical significant value (0.000), and it is less than the significance level $(\alpha=0.05)$. This means that the null hypothesis $\left(\mathrm{H}_{04}\right)$ is rejected.

- The value of the standardized coefficients (Beta) calculated for the (Internal communication) which is (0.392), show that increase of the mentioned dimension by a unity standard deviation will lead to increase the (job satisfaction) for the employees in the Islamic banks by (39.2\%).

\section{CONCLUSIONS AND RECOMMENDATIONS}

This section deals with the most important conclusions of the study, also included on the most important recommendations of the study in light of the results, which are as follows:

\subsection{Conclusions}

The study reached to a number of conclusions, among them the following:

- The results of the descriptive analysis that the evaluation level of the employees in the Islamic banks in Jordan was a (positive), for each dimension of the internal marketing dimensions 
(Empowering of employees, Training programs, Incentives and rewards, Internal communication), and with (High) degree from the perspective of the employees in the mentioned banks.

- The results of multiple linear regression analysis having the impact is statistically significant at the significance level $(\alpha=0.05)$, for three dimensions of the internal marketing (Training programs, Incentives and rewards, Internal communication), on job satisfaction for the employees in the Islamic banks.

- There exist a statistically significant impact at the significance level $(\alpha=0.05)$, for the empowering of employees on job satisfaction for the employees in the Islamic banks.

- There exist a statistically significant impact at the significance level $(\alpha=0.05)$, for the training programs on job satisfaction for the employees in the Islamic banks.

- There exist a statistically significant impact at the significance level $(\alpha=0.05)$, for the incentives and rewards on job satisfaction for the employees in the Islamic banks.

- There exist a statistically significant impact at the significance level $(\alpha=0.05)$, for the internal communication on job satisfaction for the employees in the Islamic banks.

\subsection{Recommendations}

In light of the results, the study recommended the following:

- Paying attention to Islamic banks administrations by dimension (Empowering of employees) as an internal marketing dimensions because it was ranked in (fourth) rank and last according to the employees responses in the mentioned banks.

- The study suggests on the Islamic banking administrations the necessity of print a special booklet that includes the most important directions and instructions, to be affordable for the hands of the employees and customers alike as evidence of the work on the performance of Islamic banks in Amman city.

- The researcher suggests the necessity of working future studies dealing with it other variables, different from the variables addressed in the current study, with a focus on use of other statistical techniques to address the study data that will be made in the future.

\section{REFERENCES}

[1] Abu baker, Ayman Abdullah, Impact of the internal marketing practices of on the satisfaction of the employees: A case study of Abu Dhabi Islamic Bank-Emirates, Al Ain City Branch, Journal of Economic Sciences, No. 16, 2015.

[2] Al-Hariri, Saleh Omar, Impact of the internal marketing and service quality on customers satisfaction, An applied study on sample of the Yemeni banks, $\mathrm{PhD}$ thesis (unpublished) in Business Administration, University of Damascus, Syria, 2006.

[3] Al-Haj, Amal Ibrahim \& Hani, Al-Zoumor, Impact of application of the internal marketing in job satisfaction for the sales staff in the Jordanian Telecom Group, Jordanian Journal of Business Management, Vol. 6, Issue 1, 2010.

[4] Al-Tai, Hameed \& Al-Alaak, Basheer, Principles of modern marketing (inclusive entrance), Dar Al-Yazouri for publication and distribution, $1^{\text {st }}$ Edition, Amman, Jordan, 2009.

[5] Al-Tai, Raad Abdullah \& Issa, Kdadh, Total Quality Management, Dar Al-Yazouri for publication and distribution, $1^{\text {st }}$ Edition, Amman, Jordan, 2008.

[6] An-Nsour, Iyad, Marketing strategies, A theoretical and quantitative entrance, Dar Safa for publishing and distribution, Amman, Jordan, 2012.

[7] Abdul Nabi, Mohamed Ahmed, Human resources management, Dar Zamzam Publishers \& Distributors, $1^{\text {st }}$ Edition, Amman, Jordan, 2010.

[8] Berry, L. \& Parasurman, A, Services Marketing starts from within, In Varey and Barbara, Internal marketing Directions for management, Routledg, 2000, p. 176.

[9] Dunmore, M., Inside-out Marketing, How to create on internal marketing strategy, kagan page, London (UK), 2002, p. 19. 
Impact of Application of the Internal Marketing on Job Satisfaction for the Employees in the Islamic Banks a Case Study of Jordan

[10] Souaad, Dacey \& Zaief Al-Abedi, Internal communication and its impact on job satisfaction, Faculty of economic and business sciences, Algeria, 2014.

[11] Swaidan, Nezam Muosa \& Albirdaoa, Abdul Majeed, Marketing management in non-profit organizations, Dar Al-Hamed for publication and distribution, $1{ }^{\text {st }}$ Edition, Amman, Jordan, 2009.

[12] Ryan, Omar \& Zahi, Ibrahim, Impact of the internal marketing on the employees performance in the civil society organizations, Islamic University, Gaza, 2013. 